\title{
Climate Variability and Avian Cholera Transmission in Guangxi, China
}

\section{-Author(s)}

\section{Qin $\mathrm{HY}^{\mathrm{I}}$ \\ Xiao $\mathrm{JH}^{\mathrm{L}}$ \\ Li JX' \\ Gao X \\ Wang $\mathrm{HB}$}

College of Veterinary Medicine, Northeast Agricultural University, Harbin 150030 China

\section{ABSTRACT}

In recent years, Guangxi has become one of the most severely affected provinces by epidemics of avian cholera in China. To date, the major determinant climatic factors of the disease in the region have remained largely unknown, making it difficult to effectively target countermeasures for avian cholera surveillance and control. This study aimed to quantify the relationship between climatic variables and cases of avian cholera in subtropical areas of China. Data relating to local meteorological variables and notified cases of avian cholera were supplied by the relevant authorities between January 2006 and December 2015. Spearman correlation, co-linearity statistics and crosscorrelation analysis were applied to the data, controlling for co-linearity and lag effects. A time-series Poisson regression analysis was conducted to examine the degree of correlation between the climate variables and avian cholera transmission. The results indicated that monthly mean temperature, relative humidity, rainfall and the multivariate El Niño Southern Oscillation Index, with 2-3 months lag, were correlated with avian cholera incidence. The final model had good predictive ability for the occurrence of avian cholera. Overall, the findings indicate that climate variability plays an important role in avian cholera transmission in Guangxi province. Adoption of the model presented in this study could usefully inform avian cholera surveillance strategies, making them significantly simpler and more effective. The model could also serve as a decision support tool for veterinary professionals and health authorities.

\section{INTRODUCTION}

Avian cholera is caused by the gram-negative bacterium Pasteurella multocida (P. multocida). It is a common and widely distributed disease of farmed poultry and is of major economic importance (Campi et al., 1990; Glisson et al., 2003; Singh et al., 2013b). P. multocida possesses a worldwide distribution and causes respiratory and septicemic disease in more than 180 species of birds (Samuel et al., 2007). Infection causes severe, systemic disease that is invariably fatal and highly contagious, affecting both domestic poultry and wild birds (Carter, 1966; Carver et al., 2013). Studies in poultry and turkeys have identified $P$. multocida in the mucosae of the pharynx, trachea, spleen, lungs, blood and liver of carrier chickens and turkeys (Curtis \& Ollerhead, 1981; Muhairwa et al., 2000). Outbreaks of avian cholera have been reported in Australia since the 1930's (Hart, 1938), and have also been reported widely in Europe (Christensen et al., 1998), Africa (Crawford et al., 1992), and Asia (Kwon \& Kang, 2003; Wang et al., 2009). In recent years the disease has become a particular problem in the emerging free-range layer industry in Australia (Singh et al., 2013a). It is well known that outbreaks of avian cholera are the result of complex interactions between the bacterial agent, density of birds and bacteria, and the ambient environment 
(Wobeser, 1992). And that meteorological factors are considered to play an important role in influencing the ambient environment. Epidemiological and microbiological investigations of infected flocks have been undertaken to better understand and ultimately reduce the number of outbreaks in certain countries (Snipes et al., 1987), and a range of studies have provided a good understanding of the mechanisms of transmission of avian cholera within a flock (Carpenter et al., 1996). Nevertheless, the impact of environmental conditions on flock to flock transmission is less clear.

There appears to have been no previously published reports on the quantitative relationship between meteorological variables and the transmission of avian cholera. In particular, this remains to be determined in southern China where the incidence of the disease is higher than other regions of the country, and where specific geographical features and distinct weather patterns prevail. The purpose of the present study was to quantify the relationship between climate factors and outbreaks of avian cholera in subtropical areas of China, Guangxi, in order to provide information for veterinary professionals and relevant industries operating in this area that may enable better disease control and prevention, and in particular to inform and improve the forecasting of avian cholera outbreaks and likely fluctuations in incidence.

\section{MATERIALS AND METHODS}

\section{Study area}

Guangxi Zhuang Autonomous Region is situated along the southern coast of mainland China, between latitudes $104^{\circ} 29^{\prime}$ to $112^{\circ} 03^{\prime} \mathrm{N}$ and longitudes $20^{\circ}$ $54^{\prime}$ to $26^{\circ} 23^{\prime} \mathrm{E}$. It has close borders to Vietnam and a total land area of $237600 \mathrm{~km}^{2}$ (Figure 1). Guangxi has a characteristic subtropical monsoon climate, with hot and humid summers and dry and mild winters. The subtropical monsoon climate and abundant rivers leads to frequent high temperatures, rain and floods. Guangxi was chosen as the research site in the present study because it experienced the highest percentage of cases of avian cholera in China during 2006-2015 (35.9\%). The control and prevention of avian cholera in Guangxi is therefore of high public health importance.

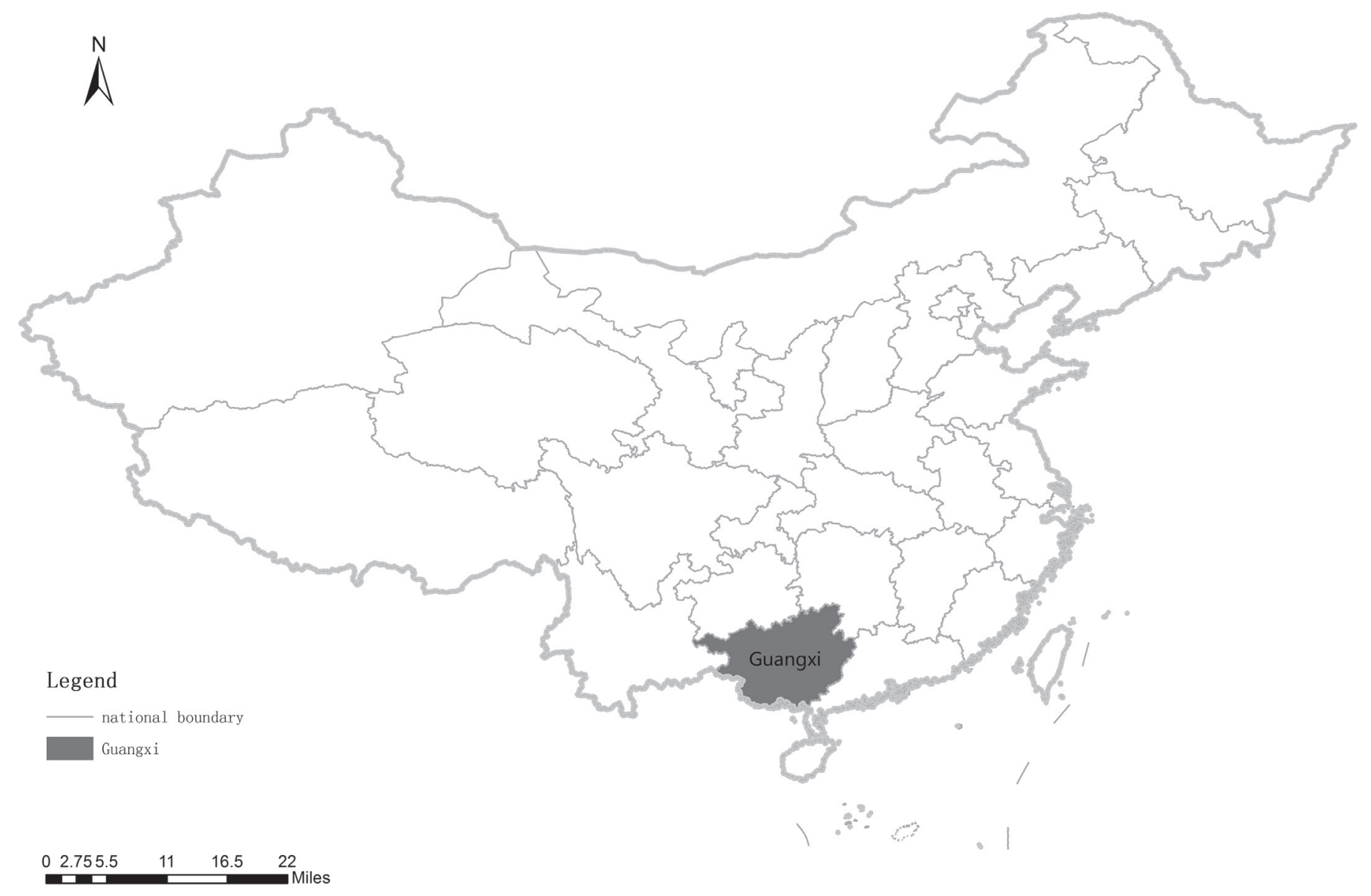

Figure 1 - Location of the study area of Guangxi Zhuang Autonomous Region, China. 


\section{Data collection and management}

Monthly records of avian cholera cases in Guangxi were obtained from the Ministry of Agriculture of the People's Republic of China (http://www.moa.gov.cn/). The Ministry publishes the Official Veterinary Bulletin monthly, which details epidemiological reports of avian cholera cases (http://www.moa.gov.cn/zwllm/tzgg/gb/ sygb/). A confirmed case of avian cholera was defined by the following clinical features: orofacial edema, swollen and edematous wattles, epicardial fatty tissue petechiae, necrotic foci on the liver, and severe respiratory disorders. Avian cholera cases confirmed after clinical symptoms, histopathological and bacteriological investigations yielded positive results. Aggregated data were available for 2006 to 2015 (10 years). Avian cholera is a Class Two animal infectious disease in China and veterinarians must report every case of avian cholera to the local veterinary authorities or animal health supervision agencies.

Local monthly meteorological data including mean temperature $\left(T_{\text {ave }}\right)$, mean minimum temperature $\left(T_{\text {min }}\right)$, mean maximum temperature $\left(T_{\text {max }}\right)$, accumulative rainfall (rainfall), and mean relative humidity $(\mathrm{RH})$ in Guangxi were obtained from the China Meteorological Data Sharing Service System (http://cdc.cma.gov. $\mathrm{cn} /$ ). Mean meteorological values were calculated by averaging data across the 88 meteorological stations in Guangxi. The El Niño Southern Oscillation (ENSO) is the most significant coupled ocean-atmosphere phenomenon affecting global climate variability and the climate in China. The Multivariate ENSO Index (MEI) was obtained from the Earth System Research Laboratory (ESRL) of the National Oceanic and Atmospheric Administration.

\section{Statistical analysis}

Following a descriptive summarization of disease incidence and meteorological variables, Spearman correlation analysis was performed to examine for associations between the various meteorological variables. Co-linearity statistics were conducted to examine the co-linearity of climate variables and to inform variable selection for the final model. Variance inflation factors (VIF) and tolerance (T) were calculated to examine the degree of multi-collinearity among the preliminary variables. Multi-collinearity was identified when the VIF was greater than 10, and indicated those multi-co-linear variables exhibiting a strong linear relationship (Myers, 2000; Zhang et al., 2012). Variable selection was identified by means of the corresponding Akaike information criterion (AIC) for the final model (McMillen, 2004).
With the purpose of identifying the lag effect of climate variables on predicting avian cholera outbreaks, a cross-correlation analysis was conducted to detect associations between avian cholera cases and climate variables for a range of lags. The significance of cross-correlations were established on the basis of $p$ values of $<0.05$ if, in turn, the cross-correlation coefficient (CCC) was larger than twice the standard error (SE). In this study, the maximum correlation coefficients of climate variables was to present the significant correlation.

With theconsideration of autocorrelation, seasonality and lag effects after correcting for overdispersion, in order to further determine the independent impact of climatic factors on the incidence of avian cholera, a time-series Poisson regression analysis was conducted. Incidence rate ratios (IRR) were calculated to evaluate the association between the determining factor and avian cholera cases. All estimates of IRR were calculated with an accompanying 95\% confidence interval $(\mathrm{Cl})$ and $\mathrm{P}$ value. The $\mathrm{R}^{2}$ value for predicting and the Ljung-Box $\mathrm{Q}$ test for autocorrelation and partial autocorrelation function of residuals, were conducted to test the goodness-of-fit of the model. All data analyses were performed in SPSS 16.0 (SPSS Inc., Chicago, IL, USA).

\section{RESULTS}

A total of 6910 reported avian cholera cases in Guangxi during the study period (2006-2015), the highest incidences were mainly distributed in Guangxi which accounted for $35.9 \%$ of the total cases across China (19266) (Figure 2). Then we checked the long

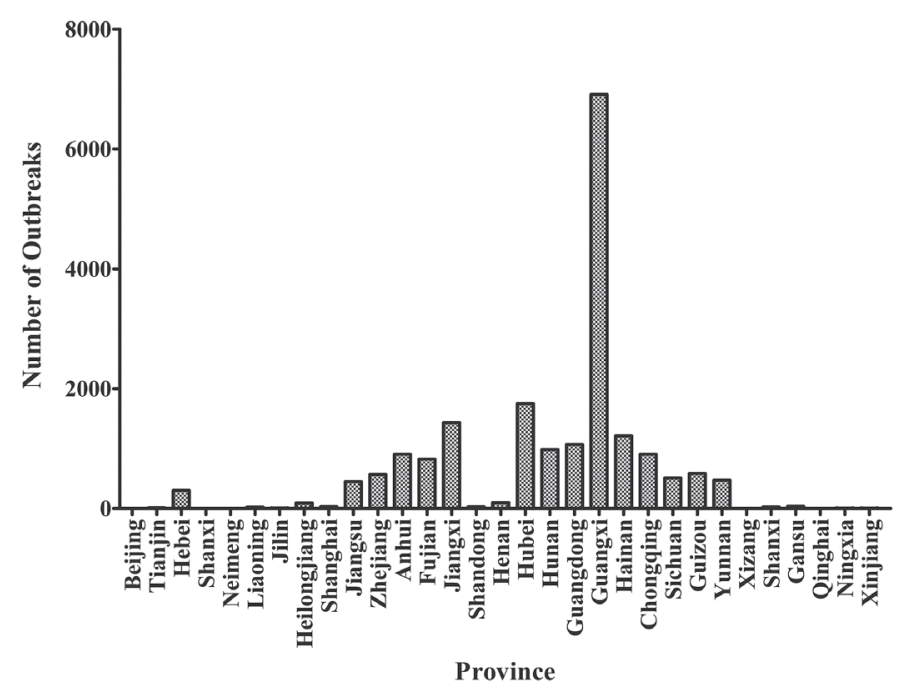

Figure 2 - Number of monthly-reported outbreaks of avian cholera per province in China from January 2006 to December 2015. 
term trend of disease cases and the annual variation of meteorological data (Figure 3), where there was a trend towards an increase in the number of cases over the study period. The temporal distribution of the whole year is average distribution (Figure 4).

The results of the spearman correlation analysis to identify associations between the various climate variables are shown in Table 1. The following variables
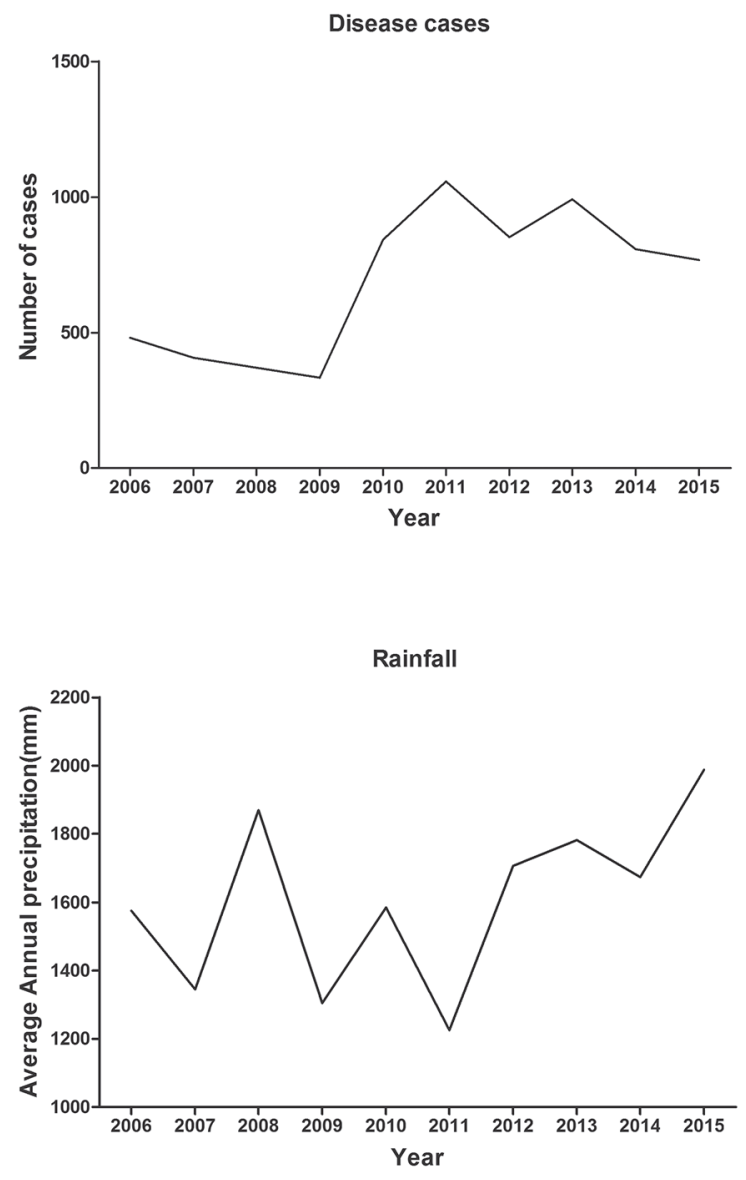

were significantly correlated with each other, with low to moderate correlation coefficients over the study period: monthly mean temperature; monthly mean maximum temperature; monthly mean minimum temperature; relative humidity; rainfall, and; MEI. According to co-linearity statistics, variance inflation factors (VIF) of the following variables: monthly mean temperature; mean minimum temperature, and;
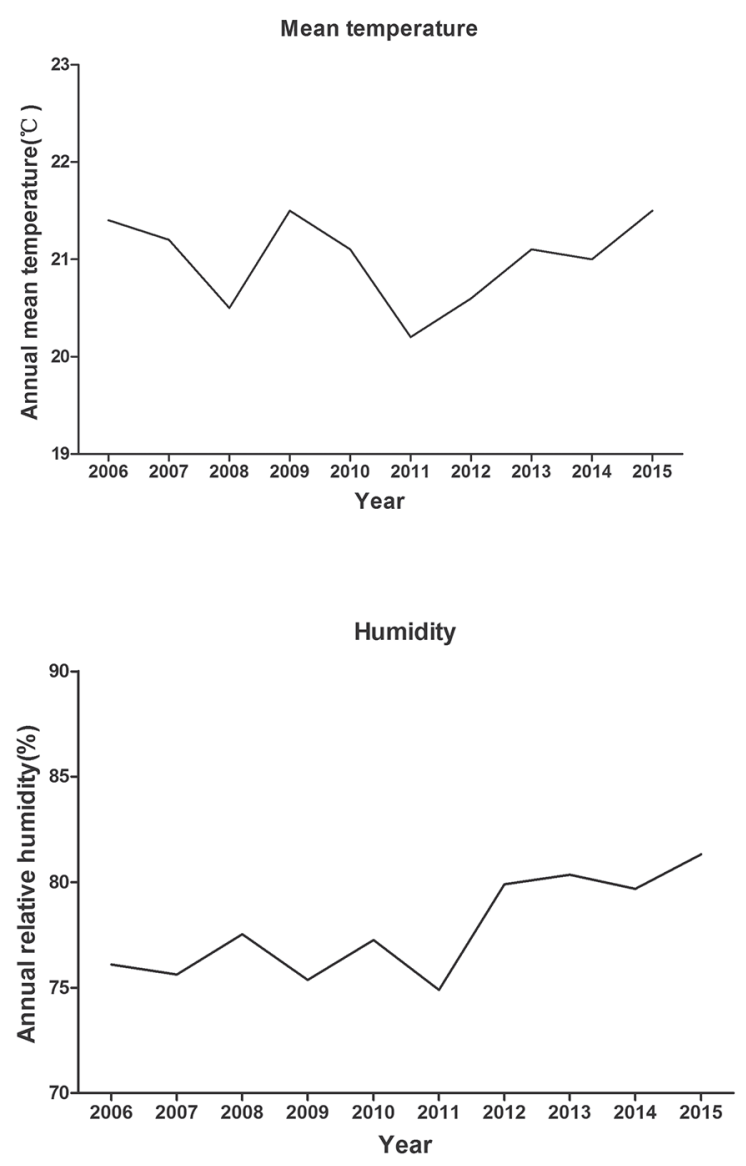

MEI

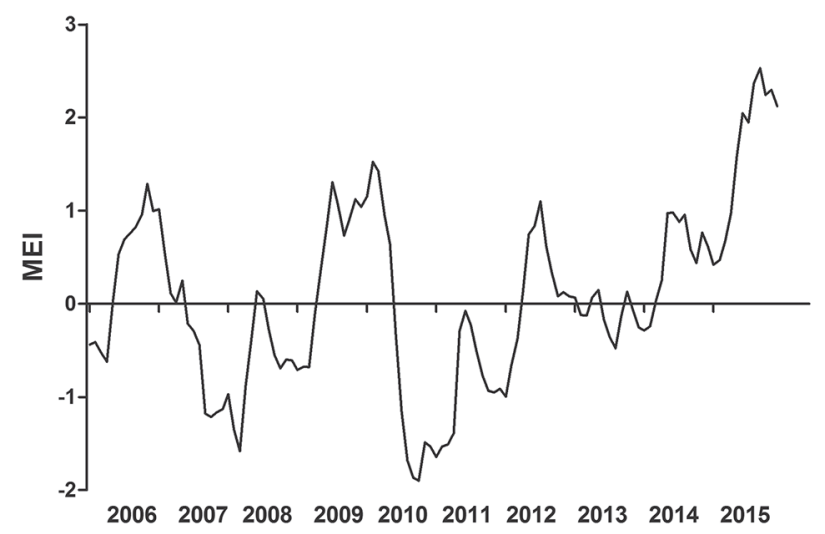

Year

Figure 3 - Long term trend of disease cases and meteorological data in Guangxi from 2006 to 2015. 


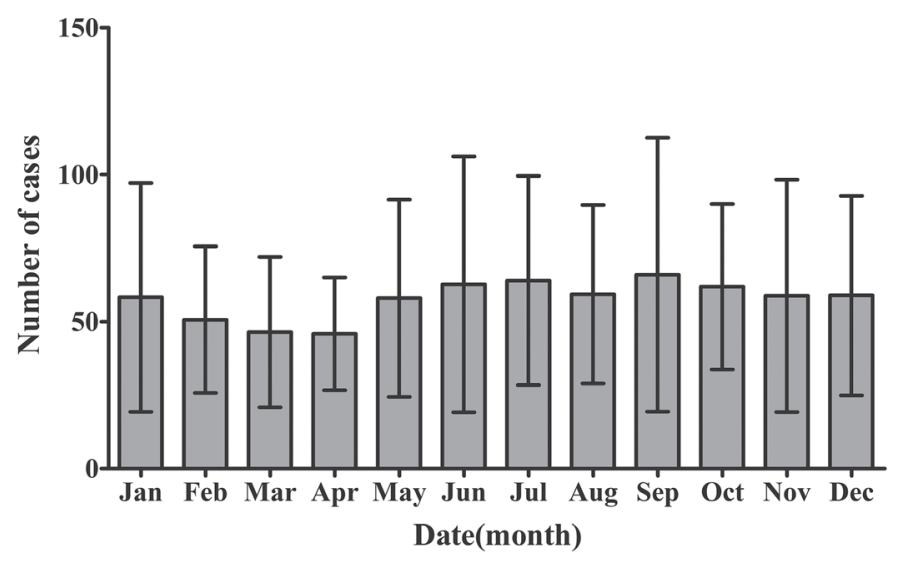

Figure 4 - The monthly distribution of the reported outbreaks of avian cholera in Guangxi.

mean maximum temperature, were higher than 10 and the tolerance values lower than 0.1 , indicating significant co-linearity between these variables (Table 2). According to the AIC criterion, monthly mean temperature was included as a predictive variable in the final model.

Table 1 - Spearman correlations coefficient between variables added into the model

\begin{tabular}{lccccc}
\hline & $\mathrm{T}_{\text {ave }}$ & $\mathrm{T}_{\max }$ & $\mathrm{T}_{\min }$ & $\mathrm{RH}$ & Rain \\
\hline $\mathrm{T}_{\text {ave }}$ & 1.000 & $0.983^{* *}$ & $0.991^{* *}$ & $0.787^{* *}$ & $0.738^{* *}$ \\
$\mathrm{~T}_{\max }$ & $0.983^{* *}$ & 1.000 & $0.945^{* *}$ & $0.722^{* *}$ & $0.675^{* *}$ \\
$\mathrm{~T}_{\min }$ & $0.991^{* *}$ & $0.945^{* *}$ & 1.000 & $0.836^{* *}$ & $0.772^{* *}$ \\
$\mathrm{RH}$ & $0.787^{* *}$ & $0.722^{* *}$ & $0.836^{* *}$ & 1.000 & $0.832^{* *}$ \\
Rain & $0.738^{* *}$ & $0.675^{* *}$ & $0.772^{* *}$ & $0.832^{* *}$ & 1.000 \\
\hline
\end{tabular}

Significance of correlation coefficient at ${ }^{* *}=p<0.01$

Table 2 - Co-linearity statistics of variables into the model

\begin{tabular}{lcc}
\hline Variables & VIF & Tolerance \\
\hline$T_{\text {max }}$ & 47.61 & 0.021 \\
$T_{\text {min }}$ & 22.24 & 0.045 \\
$T_{\text {ave }}$ & 15.71 & 0.064 \\
Hum & 2.43 & 0.412 \\
Rain & 5.77 & 0.173 \\
MEI & 8.98 & 0.111 \\
\hline
\end{tabular}

As shown in Table 3, the monthly climate variables that were significantly correlated with the reported incidence of avian cholera included mean temperature, rainfall, relative humidity and $\mathrm{MEl}$, with lags of 2 to 3 months.

Table 3 - Maximum cross-correlation coefficients between monthly avian cholera cases and climatic variables in Guangxi, China, 2006-2015

\begin{tabular}{lccc}
\hline Climate variable & Lag(month) & coefficient & $p$ \\
\hline $\mathrm{T}_{\text {ave }}$ & 3 & 0.65 & 0.000 \\
Hum & 2 & 0.36 & 0.015 \\
Rain & 2 & 0.53 & 0.000 \\
MEI & 3 & 0.25 & 0.042 \\
\hline
\end{tabular}

The Poisson regression model revealed that the occurrence of avian cholera cases was first order autoregressive, meaning that incidence in any given month was affected by meteorological conditions in the previous month. Moreover, after controlling for the autocorrelation, seasonality, and long-term trend, monthly mean temperature at a lag of 3 months, as well as monthly mean relative humidity at a lag of 2 months, accumulative rainfall at a lag of 2 months and $\mathrm{MEI}$ at a lag of 3 months, were significantly correlated with avian cholera incidence, indicating that these factors are likely to have played important roles in the transmission of avian cholera. Meanwhile, the IRRs with 95\% Cls that were calculated from the final Poisson regression model indicated that a $1^{\circ} \mathrm{C}$ increase in the monthly mean temperature may be associated with an $11.4 \%$ increase in avian cholera cases. Furthermore, it indicated that a $1 \%$ mean relative humidity rise, a 1 $\mathrm{mm}$ /day increase in monthly mean rainfall and a 1 unit rise in MEl may lead to increases of, respectively, 1.1\%, $2.9 \%$, and $55.3 \%$ in the number of avian cholera cases (Table 4). The model was tested by analyzing true

Table 4 - Time-series Poisson regression analysis of the monthly avian cholera cases on the climate variables in Guangxi, 2006-2015

\begin{tabular}{lcccc}
\hline \multirow{2}{*}{ Variable } & \multirow{2}{*}{ IRR } & \multicolumn{2}{c}{$95 \% \mathrm{Cl}$} & \multirow{2}{*}{-value } \\
\cline { 3 - 4 } & & Lower & Upper & \\
\hline Lag(case, 1$)$ & 1.014 & 1.004 & 1.025 & 0.006 \\
\hline $\operatorname{Lag}\left(\mathrm{T}_{\text {ave }}{ }^{3}\right)$ & 1.117 & 1.018 & 1.219 & 0.017 \\
Lag(Hum,2) & 1.032 & 1.012 & 1.052 & 0.000 \\
Lag(Rain,2) & 1.013 & 1.001 & 1.024 & 0.012 \\
Lag(MEl,3) & 1.551 & 1.201 & 1.896 & 0.001 \\
\hline
\end{tabular}

discrepancies between predicted data from the final multivariate model and the actual number of reported cases. A scatterplot of the results of this comparison is given in Figure 5 . The $R^{2}$ value for the predicting

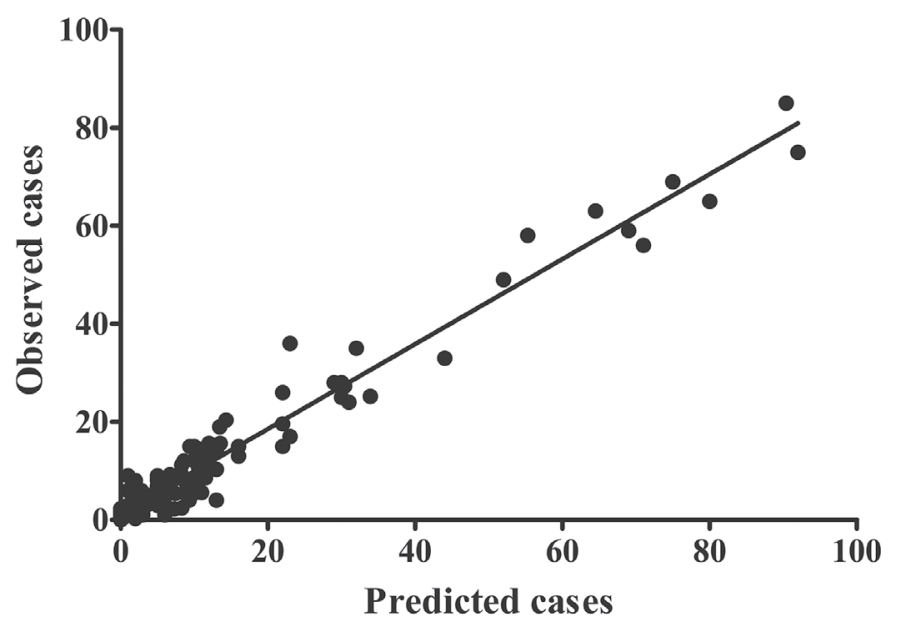

Figure $\mathbf{5}$ - Scatterplot of the final model predicted number of outbreaks versus observed number of monthly reported outbreaks of avian cholera disease in Guangxi. 
model was 0.7643 with an associated $p$ value of 0.005 . The goodness-of-fit analysis showed that the autocorrelation and partial correlation of predictive residuals at different lags were not significant (Table 5), indicating that the model had good predictive ability.

Table 5 - Autocorrelation and partial correlation of predictive residuals in Guangxi, China

\begin{tabular}{lcccc}
\hline Lag & AC & PAC & $Q_{B B}{ }^{*}$ & $p$ \\
\hline 1 & 0.286 & 0.286 & 1.2453 & 0.264 \\
2 & -0.334 & -0.452 & 3.1153 & 0.211 \\
3 & -0.134 & 0.183 & 3.4500 & 0.327 \\
4 & 0.168 & 0.009 & 4.0415 & 0.400 \\
5 & 0.072 & -0.034 & 4.1674 & 0.526 \\
6 & -0.024 & 0.094 & 4.1837 & 0.652 \\
7 & -0.166 & -0.264 & 5.1104 & 0.646 \\
8 & -0.283 & -0.182 & 8.4708 & 0.389 \\
9 & -0.109 & -0.150 & 10.466 & 0.314 \\
10 & 0.063 & -0.017 & 10.804 & 0.373 \\
\hline${ }^{*}$ liung-Box test statistic. & & &
\end{tabular}

\section{DISCUSSION}

The key finding of this study is that climate variation is an important predictor for avian cholera transmission in the subtropical monsoon regions of southern mainland China. Previous studies have debated the correlation between climate factors and transmission of infectious diseases around the world (Patz et al., 1996; Altizer et al., 2006; Zhang et al., 2010; McCormick et al., 2013; Lee et al., 2015; Rika-Heke et al., 2015), including in many areas of China (Zhang et al., 2007a; Zhang et al., 2007b; Guan et al., 2008; Huang et al., 2011; Shen et al., 2015). Outbreaks of avian cholera are known to be frequently correlated with intensive poultry production, climate stress and possible predation in free range flocks (Elfaki et al., 2002). The severity of infection is usually controlled by strict sanitation and biosecurity measures as well as by vaccination (Rimler \& Glisson, 1997). Environmental contamination during climate events, from diseased poultry or birds, is a primary source of infection and high concentrations of $P$. multocida have been found in several avian cholera outbreak related mortality events (Pearson, 2001; Waldenström et al., 2003). Thus, in the present study, we aimed to investigate the effect of climate variation on the incidence of avian cholera. The results confirmed that certain key meteorological factors, with lags 2-3 months, were strongly correlated with avian cholera incidence, and could have been used to predict avian cholera case numbers in Guangxi in the period of 2006-2015. Furthermore, our findings indicated that a potential $1{ }^{\circ} \mathrm{C}$ rise in monthly mean temperature is associated with a marked increase in avian cholera cases of up to $11.4 \%$, and that a $1 \%$ mean relative humidity rise, a $1 \mathrm{~mm} /$ day increase in monthly mean rainfall and a 1 unit rise in MEI may lead to, respectively, a $1.1 \%, 2.9 \%$, and $55.3 \%$ increase in avian cholera cases.

The control of avian cholera epidemics is a sustainability challenge and it is worthwhile understanding the root causes, including the influence of climate variation and, in particular, global warming. According to the Intergovernmental Panel on Climate Change (IPCC), an average temperature rise of 1.5$5.8^{\circ} \mathrm{C}$ has occurred across the globe during the $21^{\text {st }}$ century (IPCC 2001)(Wu et al., 2016), and the rate of global warming has been faster than expected (Carey, 2012). Rising temperature can influence both reproductive rates and the extrinsic incubation period of pathogens. Temperature is an important bio-climatic factor affecting the transmission of $P$. multocida infection via several causal pathways, including a direct impact on the proliferation of bacteria and indirect effects on feed intake and utilization by the animal host on hot days (Elijah \& Adedapo, 2006). Furthermore, at high temperatures, the thermal stress experienced by animals increases. This thermal stress results from the interaction between ambient temperature, humidity and radiant heat. Within this, ambient temperature plays the dominant role. The thermal stress response in animals is mainly associated with the activation of the hypothalamo-pituitary-adrenal (HPA) and orthosympathic nervous systems, which aggravate the detrimental effects of high body temperature. Under conditions of thermal stress, the feed consumption and metabolic activities of animals reduces, adversely affecting the rate of digestion and feed intake as well as electrolytic and water balance (Abdelqader et al., 2007; Lin et al., 2006).

In the present study, relative humidity was positively associated with the incidence of avian cholera in Guangxi. High humidity is indicative of increased moisture, which influences the survival of pathogens and adversely affects breathing, food intake and utilization by the animal host. In moist environments, the amount of water vapour that air can hold increases with temperature. High temperature combined with high humidity have negative effects on poultry physiology and performance, such as an increase in body temperature and a decrease in feed consumption (El Boushy \& Van Marle, 1978).

It has been proven that high temperature and a humid environment can reduce the activities of catalase 
and superoxide dismutase (SOD), as well as serum and liver glutathione levels inside the animals' body (Ramnath et al., 2008). This kind of response could be unfavorable to the animal's body system, since during thermal stress panting could result in oxidative stress, respiratory alkalosis and an over-production of free radicals in the body (Ramnath et al., 2008).

Variability in rainfall may have important consequences for the transmission of $P$. multocida. Rainfall, especially heavy rainfall may adversely affect the frequency and level of drinking water contamination (Zhang et al., 2007b; Zhang et al., 2010). In addition, precipitation after a long drought usually results in an increase in pathogen numbers, leading to a disease outbreak (Wilby et al., 2005). Avian cholera can be spread through ingestion of contaminated water, inhalation of water aerosols or by direct animal-to-animal contact (Botzler, 1991; Wobeser, 1992). Consistent increased rainfall will likely change the ecology of these regions and therefore the ecology of the disease (Gubler et al., 2001).

Our findings indicate a possible association between the incidence of avian cholera and the phase of ENSO. ENSO affects weather and climate variability around the world (Zhang et al., 2007b). Irregular climatic events and global warming may have a significant influence on the transmission of communicable infectious diseases, including avian cholera. MEl, as an optimal indicator of the global climate pattern, supports the concept that large-scale climate indexes may be informative for predicting patterns of disease risk, particularly within larger geographic regions at provincial or national level (Stenseth et al., 2003; Hallett et al., 2004). A given large-scale climate index may represent a better representation of climate effects than any single local weather variable (for example, a single temperature or rainfall figure)(Stenseth et al., 2003). Several human and animal infectious disease outbreaks have been shown to be influenced by the climate changes associated with the ENSO phenomenon including cholera (Pascual et al., 2000; Koelle et al., 2005), dengue (Johansson et al., 2009; Thai et al., 2010; Earnest et al., 2012), canine parvovirus (Rika-Heke et al., 2015) and rift valley fever (Anyamba et al., 2010). Previous studies have found that El Niño climate events can cause P. multocida to flourish (Traill et al., 2009), and the findings of the present study are consistent with the results of these prior studies.

To our knowledge, this is the first report on the relationship between meteorological factors and avian cholera, using existing disease surveillance data from
Guangxi province, China. The statistical methods applied to the various sources of data produced a predictive model that accounted for a high proportion of the variation in avian cholera case numbers and that predicted avian cholera incidence with good accuracy. The findings are particularly relevant to local veterinary supervision departments, with regard to their efforts to ensure healthy poultry management and to apply appropriate and timely public health interventions.

The limitations of this study should be acknowledged. Firstly, the analyses were based on official avian cholera outbreak reports, and as such the data were from passive surveillance by Veterinary supervision department. Therefore the quality of the case data is not as good as would be if gathered from active surveillance. Furthermore, underreporting is an important issue in disease surveillance systems and inevitable in the study of infectious diseases, especially animal infectious diseases. Some cases of avian cholera might go underreported due to farmers attempting to avoid economic losses and/or as a result of milder clinical symptoms being unreported. It is likely that the underreporting of cases will have influenced the precision of the model. Secondly, not all variation in the incidence of avian cholera in the study area is caused by climate alone. Other factors, including biological factors, poultry management and movement practices, poultry population density and other potentially influential socio-economic factors may also contribute to the transmission and incidence of avian cholera. Further statistical approaches need to be explored to enquire into these factors in future studies.

In summary, temperature, relative humidity, ENSO index and precipitation were among the cardinal determinants of avian cholera transmission in Guangxi, located in southern China. The findings of this study indicate that meteorological variables were important environment roles in avian cholera transmission. Climate variations have brought and will continue to bring challenges about to prevention and animal disease control. Avian cholera prevention and control measure should be undertaken with precise consideration of local climate variations. Other potential factors should be included in the future studies and such an association should be examined in other locations.

\section{ACKNOWLEDGEMENTS}

This study was financially supported by the National key R \& D program of China, No. 2016YFD0501100. 


\section{DECLARATION OF INTEREST}

\section{There is no conflict of interest with other works.}

\section{REFERENCES}

Abdelqader A, Wollny C, Gauly M. Characterization of local chicken production systems and their potential under different levels of management practice in Jordan. Tropical Animal Health and Production 2007;39(3):155-164

Altizer S, Dobson A, Hosseini P, Hudson P, Pascual M, Rohani P. Seasonality and the dynamics of infectious diseases. Ecology Letters 2006;9(4):467484.

Anyamba A, Linthicum KJ, Small J, Britch SC, Pak E, de La Rocque S, et al. Prediction, assessment of the Rift Valley fever activity in East and Southern Africa 2006-2008 and possible vector control strategies. The American Journal of Tropical Medicine and Hygiene 2010;83(2 Suppl):43-51

Botzler RG. Epizootiology of avian cholera in wildfowl. Journal of Wildlife Diseases 1991;27(3):367-395.

Campi TW, Carpenter TE, Hird DW, Snipes KP, Hirsh DC. Fowl cholera in California multiplier breeder turkeys:1985-86. Avian Diseases 1990;34(4):928-933.

Carey J. Global warming: faster than expected? Scientific American 2012;307(5):50-55.

Carpenter TE, Hird DW, Snipes KP. A time-space investigation of the epidemiology of fowl cholera. Preventive Veterinary Medicine 1996;28(3):159-163.

Carter G. Pasteurellosis: Pasteurella multocida and Pasteurella hemolytica. Advances in Veterinary Science 1966;11:321-379.

Carver C, Emery D, Straub D, Wileman B. Evidence of Serotype Cross Protection Against Fowl Cholera by Vaccination with Siderophore Receptors and Porins ${ }^{\circledR}$. Proceedings of Western Poultry Disease Conference; 2013; Sacramento. California; 2013. p.61.

Christensen J, Dietz H-H, Bisgaard M. Phenotypic and genotypic characters of isolates of Pasteurella multocida obtained from back-yard poultry and from two outbreaks of avian cholera in avifauna in Denmark. Avian Pathology 1998;27(4):373-381.

Crawford R, Allwright D, He C. High mortality of cape cormorants (Phalacrocorax capensis) off western South Africa in 1991 caused by Pasteurella multocida. Colonial Waterbirds 1992;15(2):236-238.

Curtis P, Ollerhead G. Investigation to determine whether healthy chickens and turkeys are oral carriers of Pasteurella multocida. The Veterinary Record 1981;108(10):206-207

Earnest A, Tan S, Wilder-Smith A. Meteorological factors and El Nino Southern Oscillation are independently associated with dengue infections. Epidemiology and Infection 2012;140(7):1244-1251.

El Boushy A, Van Marle A. The effect of climate on poultry physiology in tropics and their improvement. World's Poultry Science Journal 1978;34(3):155-171.

Elfaki M, Abbas B, Mahmoud O, Haroun E, Abdel-Magied E. Septicaemic pasteurellosis in ostriches (Struthio camelus) in central Saudi Arabia. The Veterinary Journal 2002;163(2):218-221.

Elijah OA, Adedapo A. The effect of climate on poultry productivity in Ilorin Kwara State, Nigeria. International journal of poultry Science 2006;5(11):1061-1068.
Glisson JR, Hofacre CL, Christensen JP. Fowl cholera. Diseases of poultry. New Jersey: Blackwell Publishing; 2003.

Guan P, Huang D, Guo J, Wang P, Zhou B. Bacillary dysentery and meteorological factors in northeastern China:a historical review based on classification and regression trees. Japanese Journal of Infectious Diseases 2008;61(5):356-360.

Gubler DJ, Reiter P, Ebi KL, Yap W, Nasci R, Patz JA. Climate variability and change in the United States:potential impacts on vector-and rodentborne diseases. Environmental Health Perspectives 2001;109(Suppl 2):223-233

Hallett T, Coulson T, Pilkington J, Clutton-Brock T, Pemberton J, Grenfell B. Why large-scale climate indices seem to predict ecological processes better than local weather. Nature 2004;430(6995):71-75.

Hart L. The occurrence of fowl cholera in Australia. Australian Veterinary Journal 1938;14(2):71-72.

Huang F, Zhou S, Zhang S, Wang H, Tang L. Temporal correlation analysis between malaria and meteorological factors in Motuo County, Tibet. Malaria Journal 2011;10:54.

Johansson MA, Cummings DA, Glass GE. Multiyear climate variability and dengue-El Nino southern oscillation, weather, and dengue incidence in Puerto Rico, Mexico, and Thailand: a longitudinal data analysis. PLoS Med 2009;6(11):e1000168.

Koelle K, Rodó X, Pascual M, Yunus M, Mostafa G. Refractory periods and climate forcing in cholera dynamics. Nature 2005;436(7051):696-700.

Kwon Y, Kang M. Outbreak of fowl cholera in Baikal teals in Korea. Avian diseases 2003;47(4):1491-1495.

Lee CCD, Tang JH, Hwang JS, Shigematsu M, Chan TC. Effect of meteorological and geographical factors on the epidemics of hand, foot, and mouth disease in island-type territory, east Asia. BioMed Research International 2015:2015:805039. DOI:1155/2015/805039.

Lin $\mathrm{H}$, Jiao H, Buyse J, Decuypere E. Strategies for preventing heat stress in poultry. World's Poultry Science Journal 2006;62(1):71-86.

McCormick B, Sanchez-Vazquez M, Lewis F. Using Bayesian networks to explore the role of weather as a potential determinant of disease in pigs. Preventive Veterinary Medicine 2013;110(1):54-63.

McMillen DP. Geographically weighted regression: the analysis of spatially varying relationships. American Journal of Agricultural Economics 2004;86(2):554-556.

Muhairwa A, Christensen J, Bisgaard M. Investigations on the carrier rate of Pasteurella multocida in healthy commercial poultry flocks and flocks affected by fowl cholera. Avian Pathology 2000;29(2):133-142.

Myers RH. Classical and modern regression with applications (Duxbury Classic). Pacific Grove: Duxbury Press; 2000.

Pascual M, Rodó X, Ellner SP, Colwell R, Bouma MJ. Cholera dynamics and El Nino-southern oscillation. Science 2000;289(5485):1766-1769.

Patz JA, Epstein PR, Burke TA, Balbus JM. Global climate change and emerging infectious diseases. Journal of the American Medical Association 1996;275(3):217-223.

Pearson GL. Field manual of wildlife diseases:general field procedures and diseases of birds. Journal of Wildlife Diseases 2001;37(1):208-211.

Ramnath $\mathrm{V}$, Rekha $\mathrm{P}$, Sujatha K. Amelioration of heat stress induced disturbances of antioxidant defense system in chicken by Brahma Rasayana. Evidence-Based Complementary and Alternative Medicine 2008;5(1):77-84. 
Rika-Heke T, Kelman M, Ward MP. The relationship between the Southern Oscillation Index, rainfall and the occurrence of canine tick paralysis, feline tick paralysis and canine parvovirus in Australia. The Veterinary Journal 2015;205(1):87-92.

Rimler R, Glisson J. Fowl cholera. Diseases of Poultry 1997;10:143-59.

Samuel MD, Botzler RG, Wobeser GA. Avian cholera. Infectious diseases of wild birds. Ames: Blackwell Publishing; 2007. p.239-269.

Shen JC, Luo L, Li L, Jing QL, Ou CQ, Yang ZC, Chen XG. The impacts of mosquito density and meteorological factors on dengue fever epidemics in Guangzhou, China, 2006-2014:a time-series analysis. Biomedical and Environmental Sciences 2015;28(5):321-329.

Singh R, Blackall PJ, Remington B, Turni C. Studies on the presence and persistence of Pasteurella multocida serovars and genotypes in fowl cholera outbreaks. Avian Pathology 2013a;42(6):581-585.

Singh $\mathrm{R}$, Remington $\mathrm{B}$, Blackall $\mathrm{P}$, Turni $\mathrm{C}$. Epidemiology of fowl cholera in free range broilers. Avian Diseases 2013b;58(1):124-128.

Snipes KP, Carpenter TE, Hird DW, McCapes RH, Hirsh DC. A descriptive study of fowl cholera in California meat turkeys: August 1985-July 1986. Avian Diseases 1987;31(4):792-799.

Stenseth NC, Ottersen G, Hurrell JW, Mysterud A, Lima M, Chan KS, et al. Studying climate effects on ecology through the use of climate indices:the North Atlantic Oscillation, El Nino Southern Oscillation and beyond. Proceedings of the Royal Society of London B:Biological Sciences 2003;270(1529):2087-2096.

Thai KT, Cazelles B, Van Nguyen N, Vo LT, Boni MF, Farrar J, et al. Dengue dynamics in Binh Thuan province, southern Vietnam:periodicity, synchronicity and climate variability. PLoS Neglected Tropical Diseases 2010;4(7):e747.

Traill LW, Bradshaw CJ, Field HE, Brook BW. Climate change enhances the potential impact of infectious disease and harvest on tropical waterfowl. Biotropica 2009;41(4):414-423.
Waldenström J, On SL, Ottvall R, Hasselquist D, Harrington CS, Olsen $B$. Avian reservoirs and zoonotic potential of the emerging human pathogen Helicobacter canadensis. Applied and Environmental Microbiology 2003;69(12):7523-7526.

Wang C, Wu Y, Xing X, Hu G, Dai J, He H. An outbreak of avian cholera in wild waterfowl in Ordos wetland, Inner Mongolia, China. Journal of Wildlife Diseases 2009:45(4):1194-1197.

Wilby RL, Hedger M, Orr H. Climate change impacts and adaptation:a science agenda for the Environment Agency of England and Wales. Weather 2005;60(7):206-211.

Wobeser G. Avian cholera and waterfowl biology. Journal of Wildlife Diseases 1992;28(4):674-682.

Wu X, Lu Y, Zhou S, Chen L, Xu B. Impact of climate change on human infectious diseases:Empirical evidence and human adaptation. Environment International 2016;86:14-23.

Zhang M, Duan H, Shi X, Yu Y, Kong F. Contributions of meteorology to the phenology of cyanobacterial blooms:implications for future climate change. Water Research 2012;46(2):442-52.

Zhang $\mathrm{Y}, \mathrm{Bi}$, Hiller JE. Climate variations and Salmonella infection in Australian subtropical and tropical regions. Science of the Total Environment 2010;408(3):524-530.

Zhang $Y$, Bi $P$, Hiller JE, Sun $Y$, Ryan P. Climate variations and bacillary dysentery in northern and southern cities of China. Journal of Infection 2007a;55(2):194-200.

Zhang Y, Bi P, Wang G, Hiller JE. El Niño Southern Oscillation (ENSO) and dysentery in Shandong province, China. Environmental Research 2007b;103(1):117-120. 
